\title{
The design process of corporate universities: a stakeholder approach
}

\section{Introduction}

In a globalized world, where competition between corporations is ever greater and changes occur at a frenetic pace, employees are one of the most valuable assets for any organization, and every successful company needs to build towards become a learning-generation environment, by developing its resources and attracting and retaining new talent (Teece et al., 1997). Within a culture of increasing knowledge importance, corporations are beginning to structure their training initiatives in a way that was once the exclusive domain of traditional universities (Brown and Seidner, 2012); in this context, corporate universities (CUs) have been conceived.

With the diffusion of these institutions, different streams of research have been developed on the topic, especially in the form of informative works about how to manage CUs (e.g., Dealtry, 2000a, 2001a; Grenzer, 2006; Rhéaume and Gardoni, 2016) or focused exploration of a single component of CUs, such as clusters of people involved (e.g., Tuchman, 2009), governance (e.g., Dealtry, 2001b), structure (e.g., Prince and Stewart, 2002), learning approaches (e.g., Fresina, 1997; Rademakers, 2014), and reporting and evaluation (e.g., Stumpf, 1998).

Despite these relevant contributions, academics and practitioners still cannot count on a comprehensive overview of how to actually design and develop a CU.

The aim of this paper is to close this gap and to propose a process to design and develop a CU driven by the goal to develop human resources competences to support business and strategic goals ( $\mathrm{Li}$ and Abel, 2011). In order to explain and explore these aspects in detail, two cases of CU design and implementation are discussed.

\section{The corporate university system: configuration and linkages with corporate strategy}

Among different organizational capabilities, education and skills enhancement represent some of the most powerful tools that firms can exploit in order to grow (Teece et al., 1997). There are many ways in which people within organizations can learn and grow (Cheetham and Chivers, 2001); among the different forms of corporate training initiatives for human resource development, CUs are viewed as one 
of the most strategic investments an organization can implement, even though onerous (Meister, 1998; Alagaraja and Li, 2015).

As a source of learning and development for companies, CUs are generally developed to build organization-specific competencies in order to enhance the ability to meet business need and performance objectives (Blass, 2005; Rademakers, 2005). Specifically, in 2002, Allen defined the nextgeneration CU to be "an educational entity that is a strategic tool designed to assist its parent organisation in achieving its mission by conducting activities that cultivate both individual and organisational learning, knowledge and wisdom" (Allen, 2002, p. 3). CUs academic debate found is flourishing period in the new millennium (Ryan et al., 2015), when scholars and practitioners have argued a lot about the strategic role of CUs in contributing to the organizational (and business) growth of the company (e.g., Dealtry, 2002; Jansink et al., 2005) and their relationship with corporate strategy (Rademakers, 2014). In particular, some authors (e.g., Hilse and Nicolai, 2004; Walton, 2005) promote CUs as a part of the organization's human capital long-term development strategy, being able to support (with effectiveness) formal learning and knowledge creation processes within an organization. Others (e.g., Waltuck, 2003; Li and Abel, 2011) support the idea that the goals of a CU are strictly linked to organizations' strategic objectives, which can be easily achieved through human capital investments. These perspectives fit with a key theory in the area of human resource development - human capital theory - which links investments in the organization's key asset (i.e., employees) to increased productivity and sustained competitive advantage (Lepak and Snell, 1999). This also supports the resource-based view of the firm: an organization develops its resources in such a way that they become rare, valuable, and difficult to imitate, in order to develop and sustain competitive advantage (Grant, 1996).

According to Allen (2007), this strategic dimension is what actually distinguishes CUs from traditional training departments: the mission to meet organizational objectives and priorities transforms CUs into a key organizational weapon, where training and learning are driven by corporate strategy, goals, and major initiatives (Andresen and Lichtenberger, 2007; Wu et al., 2010; Ben-Hur et al., 2015).

However, configuring a CU is not easy, due to the complexity of its system of operation (Dealtry, 2001b; Lui Abel and Li, 2012). Many authors focus on single building blocks of the CU system, such as: how 
to shape the relationship with corporate strategy (i.e., strategic alignment; Rhéaume and Gardoni, 2016); how to design the governance of the CU (i.e., governance; Prince and Stewart, 2002); how to define the population covered by the CU (i.e., clusters; Pedrini, 2011); how to design the learning plan for participants (i.e., learning programs; Hilse and Nicolai, 2004); how to decide the range of training methods offered by the CU (i.e., learning approaches; Rademakers, 2014); how and where to build the structure of the CU (i.e., physical organization; Dealtry, 2001a); how to choose the technological components supporting the CU (i.e., technology; Homan and MacPherson, 2005); how to evaluate learning activities outcomes (i.e., training evaluation model; Cheetam and Chivers, 2001). Other scholars described CUs through classification and evolutionary frameworks, with different approaches (e.g., Fresina, 1997; Walton, 2005; Allen, 2007; Abel, 2008; Rademakers, 2014), but only a few of them really provide a comprehensive view of how to design the whole CU system. At this regard, Prince and Stewart (2002) propose a detailed model (the "CU wheel") describing processes, elements, key actors, and duties characterizing CUs, while Dealtry (2000b) describes the CU design blocks by adapting the 10:10 RealTime Corporate University Blueprint. Rademakers (2014) positions CU in the transformational process of "acquiring new insights, skills, routines and behaviors that help to reestablish the fit between market, the business and the organizational system", distinguishing between three types of CUs: School, College and Academy, each one described in its characteristics; according to his empirical analysis, a lot of the CUs have a mix of all three types, despite a focused strategy is suggested (i.e. choose one type for supporting specific strategic goals).

\section{Configuring corporate universities: enlarging perspectives}

When setting up a CU, an interesting view is provided by Lui Abel and Li (2012), who distinguish four types of processes (and actions) that should be implemented: 1) organizational processes (i.e., establishing governance; creating a vision of the future); 2) learning delivery processes (i.e., defining who the participants will be; creating a measurement system); 3) operational processes (i.e., finding the financial sources; defining the technological support); 4) partnership processes (i.e., selecting learning partners). 
Starting from this broader perspective, the present work proposes a structured approach for managing, in a dynamic way, the CU design process, in order to clarify: 1) the sequential steps that should be followed (in particular when setting up the governance structure and the training programs); 2) the roles that are involved and what responsibilities are assigned to these; and 3) the tools supporting the execution of the design activities.

\subsection{The framework}

The preliminary process model was designed based on past contributions on CU architectural design, which clearly distinguish the architecture definition phase from its implementation, also describing the main activities of each one (Dealtry, 2000c; 2001b; Lenderman and Sandelands, 2002; Prince and Stewart, 2002; Lui Abel and Li, 2012).

\section{**Insert Figure 1 here $* *$}

The resulting model (Figure 1) is divided into two main phases: development (i.e., design of the CU structure and blocks) and management (i.e., implementation and control of the CU functions). In the first phase, the CU structure is defined, by designing: i) its strategy and positioning, ii) its architecture and learning paths, and iii) the development of courses and training events. Once the architecture is in place, the second phase realizes the actual implementation of the $\mathrm{CU}$, by: i) enrolling employees, ii) delivering the courses, and iii) ensuring a continuous control of CU training and learning efficacy.

\subsection{Methodology}

To explore the framework, we implemented action research (e.g., White, 1991; Coghlan, 2011). With this approach, a collaborative problem-solving process is established between the research team and the company, in order to solve problems and generate new solutions and knowledge (Rapaport, 1970). In our case, two companies were selected as part of the study: one from the construction industry (BE), the other from the insurance industry (CI). The research team collaborated with these organizations during the entire research period, partly as a member of the project team and partly as scholars undertaking research. In its dual role, the research team was able to influence the design processes, analyzing 
activities both with the people inside the companies and other researchers outside the system (Whyte, 1991).

Consistent with the action research philosophy, the research team followed the three-step approach proposed by McNiff (2013), and: 1) defined the general structure of the design process; 2) focused on understanding the phenomenon; 3) implemented (for both cases) the entire (and same) process, thus validating and refining the initial hypotheses. This iterative cyclical process has been carried out in collaboration with company representatives for all the phases and several top managers from different business units were involved for interviews (Table 1).

\section{**Insert Table 1 here**}

Data collected during the interviews was carefully analyzed in order to further develop the framework, which has been then implemented implanted and tested. During this process, the joint collaboration between the research and the project team enabled the iterative redefinition of the framework toward its final structure.

\subsection{Case snapshots}

Build Engineering (BE) is a multinational company operating in the construction sector, headquartered in Italy and operating globally. Due to some recent strategic decisions (a slightly shift of its core business and a growing attention on project finance activities), BE required the development of new technical and managerial competencies, and decided to support this objective by building an internal CU.

Crown Insurance (CI) is a multinational company operating in the insurance sector, headquartered in France, with an Italian network of more than 700 agencies. In the last few years, changes in customers' behavior have raised new challenges, and CI decided to react through an evolution of its distribution strategy and agency network configuration. In order to develop competencies to enable this transformation, $\mathrm{CI}$ decided to build its own $\mathrm{CU}$, targeting both agents and agency collaborators.

\section{Case analysis}


Due to the importance of $\mathrm{CU}$ development and the lack of studies on this topic, the focus of this research only embraces the development phase of the process (even though the entire process was implemented in both cases).

\subsection{Step 1: Strategy definition and positioning}

Linking the CU mission to the company strategy is essential (Meister, 1998; Allen, 2007; Rademakers, 2014); therefore, the development phase should start with the definition of the CU strategy in line with company strategic guidelines. This usually starts by defining clear roles and responsibilities for the project. Three main roles are defined: i) the sponsor - usually a top manager - who guarantees alignment between corporate and $\mathrm{CU}$ objectives; ii) the $\mathrm{CU}$ manager - the project manager - responsible for its organization and management; and iii) the scientific responsible - guarantor of the CU content quality (an internal figure or an external educational partner). The sponsor and the CU manager should first define the mission of the $\mathrm{CU}$; then, the strategic design variables are defined, in terms of targets (i.e., resources involved in the CU system, which may be selected according to professional lines, seniority, or geographical zone; Lenderman and Sandelands, 2002); and competencies (i.e., type of knowledge domains covered by the $\mathrm{CU}$ system - the more knowledge domains, the broader the field of competencies developed by the CU; Pedrini, 2011).

Table 2 summarizes characteristics of this step for the case studies:

\section{**Please insert Table 2 here $* *$}

In the $\mathrm{BE}$ case, the $\mathrm{CU}$ reports directly to the $\mathrm{HR}$ director and virtually to the $\mathrm{CEO}$. There is a single CU manager covering each area and serving as an interface for each function. Top management commitment is high — which is also thanks to the $\mathrm{CU}$ manager — and the $\mathrm{CU}$ is able to engage with and involve directors and influence resources globally. In this case, the CU has the objective to develop new managerial, technical and organizational behavior competences for all the company managerial lines, in order to support the new business directions.

In the case of $\mathrm{CI}$, the $\mathrm{CU}$ reports directly to the management committee (with the distribution director being the main sponsor), and three $\mathrm{CU}$ managers were nominated (as the project was split into three different parts). For CI, the CU objective is to effectively support the distribution network 
transformation, embedding new competences (i.e. managerial, commercial and technical skills) in all the agencies.

\subsection{Step 2: Architecture and training programs design}

The second step aims to reveal the global CU architecture and its training programs (i.e., the sequence of courses that individuals will attend).

There are four main critical decisions that should be taken within this phase (Figure 2): 1) clustering, 2) knowledge domains, 3) definition of the specific courses, and 4) design of the training programs (Figure 2).

\section{**Please insert FIGURE 2 here**}

\section{$\underline{4.2 .1 \text { Clusters }}$}

The variety of participant training needs often represents a major trade-off when designing the architecture of a CU (Analoui, 2001): defining education programs (and even single courses) coherently to take account of every single participant's needs would greatly increase the CU effectiveness, but also dramatically impact its efficiency. This is especially true when courses are intended to be company or context specific and delivered through physical classes; the dream of a training program composed of personalized courses for each individual is still largely unfeasible but, at the same time, delivering the same courses to all the participants is obviously as feasible as it is ineffective (Gustavs and Clegg, 2005). We propose to manage this trade-off by identifying clusters of participants, characterized by similar needs.

Identification of main clusters of participants can be done by the CU manager and the scientific responsible, who will both respectively bring knowledge about the specific organization and the general implementation of CUs in similar companies/industries. Clusters can then be described through a matrix crossing company roles (Figure Al).

\subsubsection{Knowledge Domains}


The second main step is the identification of the knowledge domains defined as a "homogeneous set of competences, tools and methodologies needed to support one company's main operational processes" (Alexander et al., 1994; p. 382); project management, operations management, and organizational behavior are examples of knowledge domains.

The correct definition of the knowledge domain must be inscribed in the design variables of the CU: if the $\mathrm{CU}$ encompasses single/few competences, there will be a low number of knowledge domains covered; however, if the CU targets the development of several competences (and different processes), its number of knowledge domains will be higher.

The identification of knowledge domain(s) is carried out together by the $\mathrm{CU}$ manager and the scientific responsible; the $\mathrm{CU}$ managers are also responsible for identifying internal subject matter experts (SMEs) for each knowledge domain, who will be the knowledge reference points for the scientific responsible. SMEs are normally senior managers of the company, who can contribute to the detailed analysis of the training needs (Holland and Pyman, 2006). Companies can support this step by publishing a summary document (Figure A2).

\subsubsection{Courses}

The next step involves the macro-design of the courses. The expected output is twofold: first, we expect to define which courses will be developed in each knowledge domain; second, we expect to fill in a form, for each course, encompassing main design inputs that will be provided and who will have to micro-design and deliver the course (Figure A3).

In order to identify courses in each knowledge domain, we propose a multi-step approach, with joint efforts of many different actors: the CU manager, scientific responsible, SMEs, and other selected business line managers. The basic idea is to execute a set of workshops to perform the analysis of training needs for each cluster of participants (Reynolds, 1999); in these workshops, participants will hold discussions based on a list of main concepts, tools, and methodologies that are crucial for the company in each knowledge domain, in order to identify which courses are needed per each knowledge domain and what main design specifications they might have. 


\subsubsection{Training Programs}

Finally, the last step is the design of the training program for each cluster of participants. The expected result is the definition of different paths within the same set of courses/knowledge domain (Figure A4). This step is performed together by the CU manager and the scientific responsible, and the result is normally a list of courses for each knowledge domain, progressively reduced by clustering similar courses and eliminating those with too low a number of participants. The final list will then be submitted to the manager responsible for the cluster and SMEs for approval.

This second step lead to different configuration in the two cases.

In the $\mathrm{BE}$ case, six clusters have been identified, encompassing profiles with different technical knowledge (i.e. project, procurement, operations senior, operations junior, administration, business development); this was necessary because of the wide scope of the $\mathrm{CU}$, in terms of functions and departments to be served. For example, in the operations cluster (including a variety of technical engineers and construction experts), participants were split by seniority, leaving variegated profiles together (i.e., senior and junior operations employees). In terms of knowledge domains, five key areas were identified (Economics and performance Management, Operations and Business Processes, Strategy and Innovation, Leadership and Organizational Behaviour, Project Management), each one with an internal (SME) and external (educational partner) lead. Five one-day-long workshops (one for each knowledge domain) took place, involving 25 managers and resulting in 23 courses. A tailored training program was developed for each cluster. Training programs are designed to last two or three years, with a minimum of five and a maximum 20 training days per cluster.

In the CI case, workshops resulted in the identification of three relevant clusters (i.e. agent general manager, agent insurance experts, mobile distributor), and each of the 1,000 people in the agency network could be connected with one of these profiles. In terms of knowledge domains, meetings led to the identification of four key areas (Insurance finance and risk management, Organization and human resource management, Marketing and sales, Innovation and digital transformation), each one with an internal (SME) and external (educational partner) lead. Ten half-day workshops (two for each knowledge domain) took place, involving 43 managerial positions, with the identification of 64 courses 
to be included in the training programs. Each program is designed to last 3 years, encompassing an average of 24 courses with a duration of 25 training days per year, and setting specific targets for participants to be reached in each knowledge domain (yearly competences ranking improvement; minimum knowledge based score).

\subsection{Step 3: Course development}

It is not uncommon that courses within a $\mathrm{CU}$ are developed and delivered by educational partners, who can provide the highest level of performance in different knowledge areas. The role of the CU manager in this case is to assure that these partners share the same standards and a common set of rules (Rhéaume and Gardoni, 2016). Each partner is provided with a development kit composed of two main items: i) course standards and ii) course development process.

First, every course within a CU must comply with a set of standards. Normally, this section includes the framework for the Customer Satisfaction (CS) form, the templates for the Knowledge Base Test (KBT) and the Learning Verification Test (LVT) (respectively, at the beginning and at the end of the course; Simonin, 1997), the possible formats for their implementation, and the standard reports showing the participants' results and progress. Course standards also include the ways to define and communicate the learning goals and the agenda (e.g., on a half a day basis). Finally, they include the classification of the possible teaching methodology to be adopted (e.g., lecturing, case studies, testimonials, group-work, simulations).

The development process defines the main milestones that every provider should deliver, and these include: 1) design days, 2) dry run, and 3) pilot (Riding and Sadler-Smith, 1997).

During the design days, the educational partner should meet with managers and possible participants in order to micro-design each course (e.g., agreeing about main topics on the agenda, time devoted to them, and learning methodologies adopted). A second crucial output of the design days is the engagement of managers to provide material for company-based cases and examples as well as testimonials during the delivery.

The dry run is the beta test of the course: it is an accelerated version of the course in which all the material is tested in its definitive version. Future trainers and facilitators must be present and manage 
part of the presentation, with an audience composed of managers involved in the design days, the CU manager, a sample of participants, and the scientific responsible.

Finally, the first delivery of each course can be considered to be a pilot. Feedback from participants must be retrieved with special care and attention (even the selection of the participants must be meticulous) and will provide information for further fine-tuning; only after this can the design process be considered complete.

In the $\mathrm{BE}$ case, design activities took 50 days, and four different educational partners were involved; then, dry-runs and pilots were carried out for each course.

In the CI case, design activities took 75 days, and five different educational partners were involved; dryrun and pilot were carried out only for newly developed courses ( 5 for the insurance finance and risk management area, 9 for the organization and human resource management area, 3 for marketing and sales area, and 12 for the innovation and digital management area).

\section{Discussion of findings: the linkage between $\mathrm{CU}$ design, responsibilities, and tools}

Our findings show that the proposed framework is applicable in both cases, even though project complexity and contexts are dissimilar. These variances lead to some small changes in the two solutions but the main steps, methods, and tools remain stable. In the CI case, for example, the CU project was split into three different subprojects (each one owned by a specific project manager), in order to effectively manage all of the different stakeholders, thus not realizing optimal project management conditions.

Moreover, it's important to note that the proposed process is described as a stage - gate approach, although activities are strongly correlated and interconnected; thus, a high level of flexibility is necessary, and recycling may occur (Buganza and Verganti, 2006). In the BE case, for example, much feedback was collected during the first year of implementation and, even though all the courses were first designed and developed for the entire cycle, training program plans were updated and reviewed to integrate these suggestions. The process (in terms of roles and support tools) should be then planned and configured in a flexible way. 
Moreover, our experience shows that CUs (more than any other type of training initiative), need the commitment and involvement of many organizational figures and external people (Prince and Allison, 2003). In order to ensure that CUs reach the strategic goals they have been conceived for, designing the right process and using the right tools might be not enough. As described in our cases, CUs are strongly related with the strategy of the company but their design and implementation can also require very tactical and operational skills. As with every complex process that requires the interaction of many stakeholders and decision-makers acting at very different hierarchical levels of the company, the coherence of the organization and the clear definition of boundaries and responsibilities are as important as the process itself.

With our study, we are finally able to provide a comprehensive view not only on CU design activities and support tools, but also of actors involved, roles, and responsibilities (Table 3).

\section{**Please insert TABLE 5 here**}

In designing and implementing a $\mathrm{CU}$, the $\mathrm{CU}$ manager and the scientific responsible, in particular, emerge as pivotal figures, who must guarantee a constant presence throughout the process; the sponsor should be involved only at the strategic level (i.e., definition of project organization and CU mission and objectives), while SME, other managers, and educational partners are involved in most of the operational activities (e.g., course definition, design, and implementation). This means requiring companies to make an intense organizational effort; however, their commitment represents the key factor for a successful implementation of the CU as a sustainable training structure for skills and talent development in the long term (Wang et al., 2010; Alagaraja and Li, 2015).

\section{Conclusions}

This papers aims to contribute to the actual debate on how to develop skills and talent in modern companies (e.g. Reynolds, 1999; Mayfield et al., 2016) by proposing a process framework for CU design and development; coherently with the action research approach, this model was iteratively shared and reviewed with two companies attempting to implement their own CUs in order to support business objectives and resource development. 
Our findings are intended to be relevant in two ways.

From an academic point of view, our work contributes to a broader stream of research on possible frameworks for CU design and management, tested theoretically (e.g., Dealtry, 2000c) or empirically (e.g., Lui Abel and Li, 2012). Although similar approaches are already present in the literature (i.e., CU wheel by Prince and Stewart (2002) or the 10:10 RealTime Corporate University Blueprint by Dealtry (2000b)), the theoretical framework we obtained represents an attempt to position these different perspectives about CU within the same model, providing a holistic and complete model instead of focusing on single aspects. Moreover, if compared with previous studies, our work is different in two ways. First, we tried to accumulate existing theories and findings instead of proposing a new one; and, second, we go beyond the theoretical proposal (e.g. Walton, 2005; Li and Abel, 2011; Rhéaume and Gardoni), testing it for real implementation through action research. Our model confirms the dynamic nature of the process (in its details on both the development phase and the management phase of the $\mathrm{CU})$, which is unique in its type and form, and can be used as a reference framework for future studies on CU design.

From a managerial perspective, our work provides a real blueprint not only for design but also for implementing a CU. The process is divided into main phases and single actions and tools and insights from the real cases provided. As the process embraces all kinds of activities ranging from strategic to operative ones, our work also provides managers with an organizational tool to identify the main roles and describes the most important ones in order to define their accountability and boundaries throughout the process.

This study also has some limitations. First, we present a two-step framework, but we only include results and comments on the development phase, as we first want to deal with the more strategic aspects and activities of CU design, leaving aside operational implications. Future research can be shaped around the exploration of specific activities, roles, and tools for the on-going management of this system. Secondly, our framework has been refined and validated using two specific cases; in order to increase its generalizability, future research can work toward its application in other organizations and industrial contexts, thus contributing to refining its structure. 


\section{References}

Alagaraja, M. \& Li, J. (2015). Utilizing institutional perspectives to investigate the emergence, rise and (relative) decline of corporate universities. Human Resource Development International. 18(1), 4-23.

Alexander, P. A., Kulikowich, J. M., and Schulze, S. K. (1994). The influence of topic knowledge, domain knowledge, and interest on the comprehension of scientific exposition. Learning and Individual Differences, 6(4), 379-397.

Allen, M. (2002). The corporate university handbook: Designing, managing, and growing a successful program. AMACOM Div American Mgmt Assn.

Allen, M. (2007). The next generation of corporate universities: Innovative approaches for developing people and expanding organizational capabilities. John Wiley and Sons.

Analoui, F. (2001). Management education and increased managerial effectiveness, 20(9): 785-794.

Andresen, M., and Lichtenberger, B. (2007). The corporate university landscape in Germany. Journal of Workplace Learning, 19(2): 109-123.

Ben-Hur, S., Jaworski, B., and Gray, D. (2015). Aligning Corporate Learning With Strategy. MIT Sloan Management Review, 57(1), 53.

Blass, E. (2005). The rise and rise of the corporate university. Journal of European Industrial Training, 29(1): 5874.

Brown, S. M., and Seidner, C. J. (2012). Evaluating corporate training: Models and issues (Vol. 46). Springer Science and Business Media.

Buganza T., Verganti R. (2006) "Life-Cycle Flexibility: how to measure and improve the innovative capability in turbulent environments", Journal of Product Innovation Management; Vol. 23(5), 393-407.

Cheetham, G., and Chivers, G. (2001). How professionals learn in practice: an investigation of informal learning amongst people working in professions. Journal of European Industrial Training, 25(5): 247-292.

Coghlan, D. (2011). Action research: Exploring perspectives on a philosophy of practical knowing. The Academy of Management Annals, 5(1), 53-87.

Dealtry, R. (2000a). Case research into the evolution of a corporate university development process. Journal of Workplace Learning, 12(8): 342-357.

Dealtry, R. (2000b). Establishing a methodology for appraising the strategic potential of the corporate university. Journal of Workplace Learning, 12(5): 217-224.

Dealtry, R. (2000c). Strategic directions in the management of the corporate university paradigm. Journal of Workplace Learning, 12(4): 171-175.

Dealtry, R. (2001a). Configuring the corporate university - managing a portfolio of thinking schools. Journal of Workplace Learning, 13(1): 30-38.

Dealtry, R. (2001b). How to configure the corporate university for success. Journal of Workplace Learning, 13(2): 73-79.

Dealtry, R. (2002). Managing the corporate university watershed. Journal of Workplace Learning, 14(6): 256261.

Dealtry, R. (2005). Achieving integrated performance management with the corporate university. Journal of workplace learning, 17(1/2), 65-78.

Eccles, G. 2004. Marketing the corporate university or enterprise academy. Journal of Workplace Learning, 16(7): $410-418$.

Fresina, A. (1997). The three prototypes of corporate universities. Corporate University Review, 5(1), 3-6.

Grenzer, J. W. (2006). Developing and implementing a corporate university. Human Resource Development.

Grant, R. M. (1996). Toward a knowledge-based theory of the firm. Strategic management journal, 17(S2), 109122.

Gustavs, J., and Clegg, S. (2005). Working the knowledge game? Universities and corporate organizations in partnership. Management Learning, 36(1), 9-30.

Hilse, H., and Nicolai, A. T. (2004). Strategic learning in Germany's largest companies. The Journal of Management Development, 23(3/4): 372-398.

Holland, P., and Pyman, A. (2006). Corporate universities: catalyst for strategic human resource development? Journal of European Industrial Training, 30(1): 19-31.

Homan, G., and Macpherson, A. (2005). E-learning in the corporate university. Journal of European Industrial Training, 29(1): 75-90.

Jansink, F., Kwakman, K., and Streumer, J. (2005). The knowledge-productive corporate university. Journal of European Industrial Training, 25(1): 40-57.

Lenderman, H., and Sandelands, E. (2002). Learning for a purpose: building a corporate university. International Journal of Contemporary Hospitality Management, 14(7): 382-384.

Lepak, D. P., and Snell, S. A. (1999). The human resource architecture: Toward a theory of human capital allocation and development. Academy of management review, 24(1), 31-48. 
Li, J., \& Abel, A. L. (2011). Prioritizing+ Maximizing the Impact of Corporate Universities. T+ D Magazine, 65(5), 54-57.

Lui Abel, A., \& Li, J. (2012). Exploring the corporate university phenomenon: Development and implementation of a comprehensive survey. Human resource development quarterly, 23(1), 103-128.

Mayfield, M., Mayfield, J., Wheeler, C. (2016) "Talent development for top leaders: three HR initiatives for competitive advantage", Human Resource Management International Digest, Vol. 24 Iss: 6, pp.4 - 7

McNiff, J. (2013). Action research: Principles and practice. Routledge.

Pedrini, G. (2011). The Corporate University Phenomenon and the Competences "Pipeline": The Role of Innovation and Institutional Change. Journal of US-China Public Administration, 8(9): 1004-1015.

Prince, C., and Allison, S. (2003). Corporate university developments in the UK SME sector. Journal of Workplace Learning, 15(5): 229-239.

Prince, C., and Stewart, J. (2002). Corporate universities - an analytical framework. Journal of Management Development, 21(10): 794-811.

Rademakers, M. 2005. Corporate universities: driving force of knowledge innovation. Journal of Workplace Learning, 17(1/2): 130-136.

Rademakers, M. (2014). Corporate universities: Drivers of the learning organization. Routledge.

Rapoport, R. N. (1970). Three dilemmas in action research with special reference to the Tavistock experience. Human relations, 23(6), 499-513.

Reynolds, M. (1999). Critical reflection and management education: Rehabilitating less hierarchical approaches. Journal of Management Education, 23(5), 537-553.

Rhéaume, L., \& Gardoni, M. (2015). The challenges facing corporate universities in dealing with open innovation. Journal of Workplace Learning, 27(4), 315-328.

Rhéaume, L., \& Gardoni, M. (2016). Strategy-making for innovation management and the development of corporate universities. International Journal on Interactive Design and Manufacturing, 10(1), 73-84.

Riding, R. J., and Sadler-Smith, E. (1997). Cognitive style and learning strategies: Some implications for training design. International Journal of Training and Development, 1(3), 199-208.

Ryan, L., Prince, C., \& Turner, P. (2015). The changing and developing role of the corporate university postmillennium. Industry and Higher Education, 29(3), 167-174.

Simonin, B. L. (1997). The importance of collaborative know-how: An empirical test of the learning organization. Academy of management Journal, 40(5), 1150-1174.

Stumpf, S. (1998). Corporate universities of the future. Career Development International, 3(5): $206-211$.

Teece, D. J., Pisano, G., and Shuen, A. (1997). Dynamic capabilities and strategic management. Strategic management journal, 18(7), 509-533.

Tuchman, G. (2009). Wannabe U: Inside the corporate university. University of Chicago Press.

Walton, J. (2005). Would the real corporate university please stand up? Journal of European Industrial Training, 29(1): 7-20.

Wang, G.G., Li, J., Qiao, X. \& Sun, J. Y. (2010). Understanding the corporate university phenomenon: A human capital theory perspective. International Journal of Human Resource Development and Management. 10(2), 182-204.

Waltuck, B. (2003). Strategic learning: Corporate universities and organizational improvement. In American Society for Quality. Proceedings of ASQ's 57th Annual Quality Congress. Expanding horizon: global, personal, tools, networking, solutions (pp. 195-197).

Whyte, W. F. E. (1991). Participatory action research. Sage Publications, Inc. 